\title{
Influence of concrete strength and diameter of reinforcing bar on pullout tests using finite element analysis
}

\author{
K. Senthil*, S. Bawa and C.P. Aswin \\ Dr. B.R. Ambedkar National Institute of Technology Jalandhar, Department of Civil Engineering, Punjab, \\ India
}

\begin{abstract}
The numerical investigations have been carried out on simulating bond-slip behaviour between concrete and steel reinforcing bar using ABAQUS explicit finite element code. The major contribution of this paper is to study the influence of varying concrete strength and diameter of reinforcing bar on bond slip behaviour. The inelastic behaviour of concrete and steel reinforcing bar were defined using concrete damaged plasticity model and Johnson-Cook model respectively which is available in ABAQUS/CAE. A spring-translator element available in ABAQUS, was used to simulate the bond slip phenomena in reinforced concrete during pull-out. The results thus predicted through simulations were compared with the experimental results available in literature. It was observed that the translator used in the present study simulates the bond behaviour efficiently. It was also observed that the predicted and measured deformed profile was found in good agreement. Further, the simulations were conducted on principal parameters to study the influence of concrete compressive strength and the bar diameter. In case of $40 \mathrm{MPa}$ concrete the bond stress improved by $60 \%$ when $16 \mathrm{~mm}$ diameter bars were replaced by $20 \mathrm{~mm}$ diameter bars. Increasing the bar diameter is an efficient method to improve the bond strength characteristics. However, the improvement in bond stress was found to be insignificant when concrete strength was increased from $60 \mathrm{MPa}$ to $100 \mathrm{MPa}$.
\end{abstract}

\section{Keywords}

Bond-slip simulation; Numerical model; Concrete strength; Size of reinforcing bar; Deformation

Received: 25 July 2018; Accepted: 07 September 2018

ISSN: 2630-5763 (online) @ 2018 Golden Light Publishing® All rights reserved.

\section{Introduction}

The bond between steel and concrete is very important and essential so that it can act together without any slip in a loaded structure. The design of structural members is based on a fundamental assumption that there exist an effective bond linking between concrete and steel and there is no slipping between concrete and steel reinforcement. It is assumed in all design calculation that the steel resist the tension force, and the change in tension force in concrete is transmitted to the concrete by a surface stress. The interaction between concrete and steel is a complex phenomenon which depends on several factors such as friction, mechanical interaction and chemical adhesion. These complex phenomena led engineers to depend mainly on empirical formulas derived from the experiments for the calculation and design of structures. Number of experimental investigations has been carried out to understand the behavior deformed bars through pull out tests under monotonic loading. Jiang et al. [1] developed new test method by cutting the

* Corresponding author

E-mail: urssenthil85@yahoo.co.in 
reinforcing bars into two halves and placing in two opposite sides of the cross section to study the local slip, secondary cracking and strain distribution in concrete surrounding the interface. Soroushian and Choi [2] reported on local bond strength of deformed bars with different diameters in confined concrete. It was also observed that the influence of strength of concrete with different confinements. It was concluded that the bond strength found to be decreased as the bar diameter increases. Abrishami and Mitchell [3] developed a new testing technique, which simulates uniform bond stress distribution along a reinforcing bar. These testing technique have been used to investigate the bond performance of reinforcing bars and pre-stressing strands. Malvar [4] conducted experiments on twelve specimens of $75 \mathrm{~mm}$ diameter cylinder having six number of reinforcing bar to determine the local bond stress-slip response. The radial confining stress around the concrete specimen and radial deformation, together with bond stress and slip, were assumed to be fundamental variables needed to describe the interface behavior properly. The configuration independent bond stress versus slip relationships for a short five lug embedded length were obtained for various degrees of confining pressure. It was concluded that maximum bond stresses found increased almost threefold by increasing the confinement stress from 500 to 4500 psi at the bar level.

Yankelevsky et al. [5] developed mathematical model to predict the bond versus slip relationship of the systems against cyclic loading is represented by three major resistance components that appear to control the behavior and changing their influence, at various loading stages. The model was developed according to experimental bond versus slip tests for well-confined concrete available in the literature. The results thus predicted through model are compared with experimental results and found in good agreement. Harajli et al. [6] conducted experiments on local bond between steel bars and concrete confined with ordinary transverse steel and the results were compared with the results of similar specimens confined either internally using steel fiber reinforcement or externally using fiber- reinforced polymer (FRP) sheets. On the basis of comparisons, a unified expression for the local bond strength of confined concrete is derived, and a general model for the local bond stress versus slip response is proposed and used to conduct an analytical estimation of the effect of confinement on development/splice strength. The results predicted through the analysis were in good agreement with experimental results. $\mathrm{Li}$ [7] conducted a finite element analysis on the bond-slip relationship between concrete and reinforcement to simulate the bond behavior using ABAQUS. It is concluded that the spring like translator was very good in predicting the bond behavior either for linear, bilinear or even nonlinear conditions. Shafaie et al. [8] conducted finite element analysis on modeling of the transition region between steel and concrete as a cohesion layer using ANSYS commercial finite element tool. The accuracy of the models was assessed by comparison of the finite element simulation results with the experiments. The finite element studies on short embedment length shows relatively good agreement as compare to experimental results. Study on the pullout strength of ribbed bars in high strength concrete was carried out by [9]. The influence of bond lengths of 50 and $150 \mathrm{~mm}$ with varying bar diameter, strength of concrete and type of confinement and with confinement using spiral ties was studied. It was observed that the maximum bond stress for unconfined concrete about $60 \%$ of that of those confined with spirals. Also it was observed that the influence of bar diameter on the local bond stress slip relationship was rather small in the tested range. The bond strength also decreased as the embedment length increased. Barbosa and Filho [10] carried out experiments on pull out specimens with high strength concrete and three different bars of diameter. The experimental result in terms of bond stress versus slipping were also compared with CEB provisions and with some theoretical formulations available in literature. It was observed that the bond stress versus slipping response for ordinary and the high strength concrete were same. It was also observed that with increase of bar diameter the bond stress increases. 
Filho and Debs [11] carried out numerical investigations on the bond stress behavior of 10 and $16 \mathrm{~mm}$ diameter steel bars embedded in 305 and $611 \mathrm{kgf} / \mathrm{cm}^{2}$ self-compacting concrete (SCC) and in Ordinary Concrete. The pre peak branch of the load versus slip curve for all specimen with different concrete and strength and bar size showed satisfactory results. Prince and Singh [12] studied on the bond behavior of normal and high strength recycled aggregate concrete (RCA) with the replacement levels of 25, 50, 75 and 100\%. The measured bond versus slip relationships indicates similar mechanisms of bond resistance in the RAC and the natural aggregate concrete for all the grades and relatively the most accurate and least conservative predictions of the measured bond strengths were obtained from the local bond versus slip model in the FIP Model 2010. Xing et al. [13] conducted experiments on pull out test to assessment of bond performance and influence of embedment length, surface type (Plain and deformed) of reinforcing bars, and bar diameter. The results indicated that the bond stress experienced by plain bars is quite lower than that of the deformed bars given equal structural characteristics. In general, plain bars appeared to develop only $18.3 \%$ of the bond stress of deformed bars.

Based on the detailed literature survey, it has been observed that the experiments have been well documented in specific literature. However, to better understand the bond behavior a reliable bond model that can be employed in three dimensional finite element analysis is needed. Also, it is observed that few studies available in literature are carried out using finite element method however the parameters influencing the bond stress were not studied. Finite element techniques are becoming popular since a number of parameters can be varied with ease when compared with experiments which are costlier and time consuming. The need of better representation of bond behavior of steel concrete interface the absence of data for the evaluation of bond strength and very few literatures on the numerical modelling of pullout test gave the motivation for this research. In the present study, the bond slip behavior of reinforced concrete systems experienced between concrete and steel have been studied using the finite element packages ABAQUS. The accuracy of model is verified by comparing the numerical results with that results measured from the experiments available in literature, [13]. In addition to that, the parametric study has been conducted to study the factors influencing the bond stress behavior such as varying strength of concrete and the diameter of steel reinforcement bar.

\section{Numerical study}

The present section covers numerical and analytical modelling of bond behavior on reinforced concrete systems. The numerical modelling was based on the finite element software ABAQUS/CAE was capable of modelling reinforced concrete response, including the bond-slip behavior experienced between concrete and steel is discussed here.

\subsection{Geometric modelling}

The specimen is a cube of dimension $(200 \times 200 \mathrm{x}$ $200 \mathrm{~mm}^{3}$ ) with a deformed reinforcing bar of 16 $\mathrm{mm}$ embedded in it and both was modelled as deformable body. The dimensions of the model were so given that it was the same as used in the experimental work. Modelling of the reinforced concrete cube involves the three dimensional modelling of the concrete cube and that of the rebar. These independent parts are created and then assembled together and assigned suitable interaction properties and constraints between their surfaces to form the numerical model.

\subsection{Constitutive modelling}

Constitutive behavior of concrete is very difficult to capture by using elastic damage models or elastic plastic laws. In elastic damage model irreversible strains cannot be captured. It can be seen that a zero stress corresponds to a zero strain which makes damage to be overestimated. On the other hand, when elastic plastic relation is adopted the strain will be overestimated since the unloading curve will follow the elastic slope. Concrete Damaged 
Plasticity model which combines these two approaches can capture the constitutive behavior of experimental unloading. Concrete Damaged Plasticity (CDP) model is one of the possible constitutive models to predict the constitutive behavior of concrete. It describes the constitutive behavior of concrete by introducing scalar damage variables. Interface behavior between rebar and concrete is modelled by implementing tension stiffening in the concrete modelling to simulate load transfer across the cracks through the rebar. Tension stiffening also allows to model strain softening behavior for cracked concrete. Thus it is necessary to define Tension stiffening in Concrete Damage Plasticity model. ABAQUS [14] allows us to specify Tension Stiffening by post failure stressstrain relation or by applying a fracture energy cracking criterion. Concrete of M20 cube was considered in the modelling. Mass density of concrete was taken as $2400 \mathrm{~kg} / \mathrm{m}^{3}$. The young's modulus of the concrete was taken as equal to $25491 \mathrm{~N} / \mathrm{mm}^{2}$. Poisson's ratio was taken as 0.18 . Concrete damage plasticity model was considered with dilation angle is 31 , eccentricity $0.1, \mathrm{~K}$ is 0.667 and $f_{b} / f_{c o}$ is equal to 1.16 . The stress versus strain for compression (Series 1) and tension (Series 2) of concrete was considered is shown in Fig. 1.

The material behavior of the steel reinforcement was incorporated using the well-known JohnsonCook [15] elasto-viscoplastic material model that is capable of predicting the flow and fracture behavior of the ductile materials.

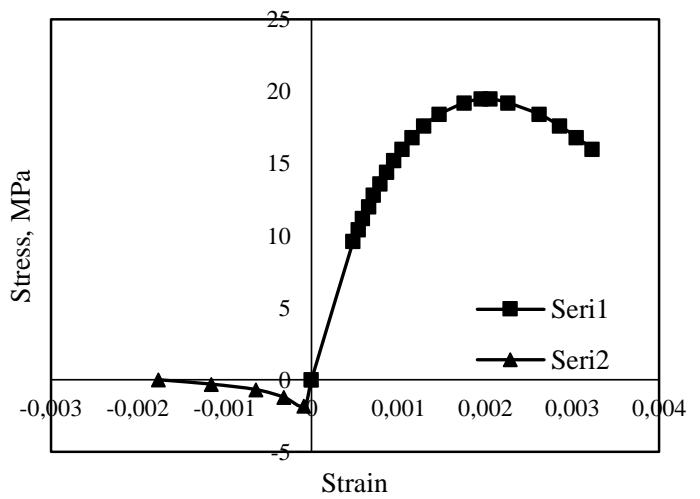

Fig. 1. Stress-strain relationship of concrete under tension and compression
It includes the effect of linear thermo-elasticity, yielding, plastic flow, isotropic strain hardening, strain rate hardening, softening due to adiabatic heating and damage. The Johnson-Cook parameters for steel reinforcement bar considered in the present study was obtained from the work carried out by Borvik et al. [16].

\subsection{Modelling of connector and application of loading}

The most important step in modelling was in deciding the method for building a contact between concrete and steel. Nilson [17] used a double spring element to model the bond slip phenomena, with one spring acting parallel to the bar axis and one acting perpendicular to it. In ABAQUS a special element i.e. spring element whose stiffness is based on force displacement is available. The element will be the best choice for representing Nilson's double spring bond model. The behavior of spring can be defined both in linear and nonlinear behavior. Another commonly used tool in ABAQUS to describe the contact behavior of two surfaces is friction. The process of using the friction model is that it uses surface to surface contact unlike the spring element which uses node to node interaction. But the main drawback of this method is that this model cannot simulate nonlinear bond behavior as well as the degrading portion of the graph. In Fig. 2a it is seen clearly that the relation between the yellow and blue portion quite resembles the bond relationship between concrete and the reinforced steel bar. The translator element was used to connect the nodes one by one at the interface between steel and the concrete at equal intervals along the length of the rebar. The bond slip was assumed to follow a spring like behavior in the pull out direction that is the longitudinal direction. In the other direction it was assumed that they show a hard contact with the interface involving a master slave relationship. The relative motion is restricted to only $\mathrm{u}_{1}$ direction i.e. translation in direction parallel to blue bar axis. The interaction between parts in other direction in translator is taken as hard contact. The partition cells were created in the concrete part as well as at 
the steel part so as to like the translator in ABAQUS node to node. The wire feature was used to connect the nodes. As shown in Fig. 2b translator was assigned at four different location on the rod and throughout the length of the bar. The loading was applied at the free end of the reinforcing bar as was done in the experimental setup. The applied loading consisted of an axial displacement imposed at the exposed end of the rebar applied in the pull out direction. A displacement controlled loading of $1.51 \mathrm{~mm} / \mathrm{min}$ was applied at the free end. The loading was given with the help of load module and boundary condition manager. The load was given in the boundary condition manager so that the displacement only occurs in the direction of pull i.e. U3 and the other two directions it is fixed. To accurately simulate the effect of pull out test as in experimental setup a fixed boundary condition was assigned on the four surfaces of the block as shown in Fig. 2c.

\subsection{Mesh convergence study}

Concrete and steel has been modeled as a deformable body with geometrical dimensions same as followed in the experimental setup [13]. The material property of concrete was given as per concrete damage plasticity model and that of steel as given by Jonson-cook-damage model. The mesh convergence has been carried out to understand the mesh sensitivity of simulated concrete block. The mesh convergence study models of varying mesh sizes of 5, 10 and $40 \mathrm{~mm}$ are shown in Fig. 3. The results obtained with the three cases of mesh of finite element simulations were compared with the experimental results, see Fig. 4. Overall, the results were found to be insensitive of mesh size. However, the fine mesh with approximate global size of $10 \mathrm{~mm}$ among the chosen configurations was found to give accurate result which was very much satisfactory and converging. The very fine mesh with global size of $5 \mathrm{~mm}$ was also found to give converging result similar to that of $10 \mathrm{~mm}$. Although, the variation between the fine mesh and very fine mesh results were very negligible. So mesh size with approximate global size of $10 \mathrm{~mm}$ was adopted for further study.

\section{Comparison of experimental and numerical results}

The deformed profiles obtained through numerical simulations was compared with the experimental results [13]. It was observed that the deformed profile in both experimental and numerical results are found in good agreement, see Fig. 5. The side view as well as top view of the deformed profile of the model in the $\mathrm{Y}-\mathrm{Z}$ and $\mathrm{X}-\mathrm{Y}$ directions, respectively were shown in Fig. 6. From the deformed profile it can be clearly stated that the regions nearer to the loaded end experienced higher stress. It was seen from the deformed profile that regions closer to the rebar experienced higher stress than that of the regions farther away from it. The grey colored portion in the deformed profile represents the reinforcing bars.

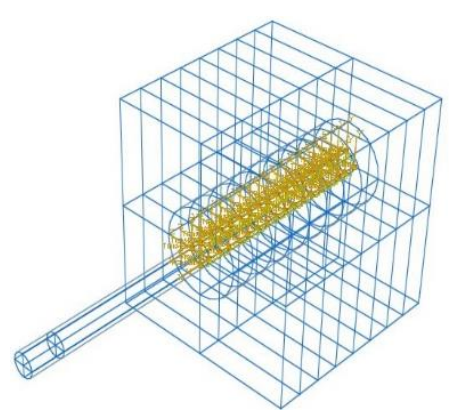

a) isometric

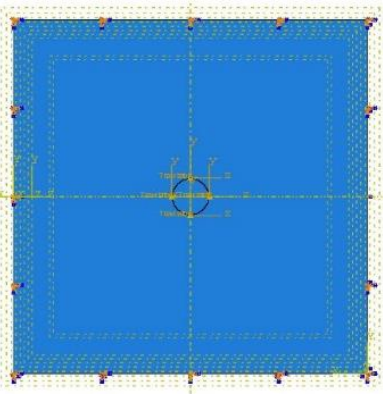

b) front view

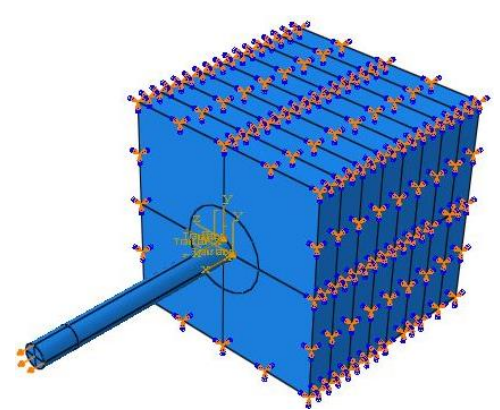

c) boundary condition

Fig. 2. Modelling of translators 


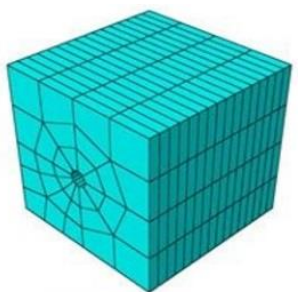

a) $40 \mathrm{~mm}$ mesh size

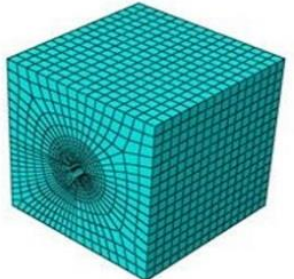

b) $10 \mathrm{~mm}$ mesh size

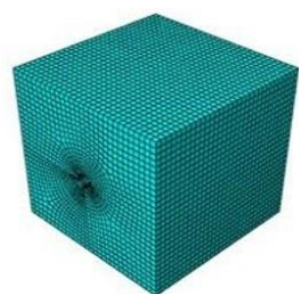

c) $5 \mathrm{~mm}$ mesh size

Fig. 3. Finite element model

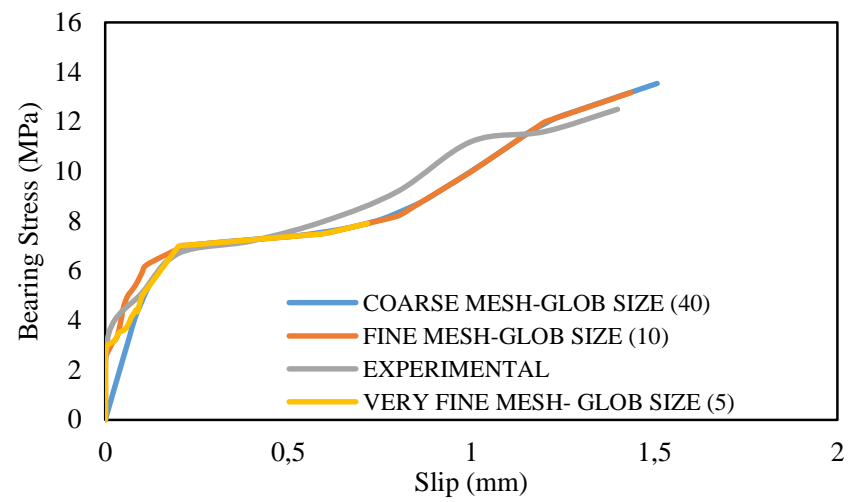

Fig. 4. Mesh convergence study

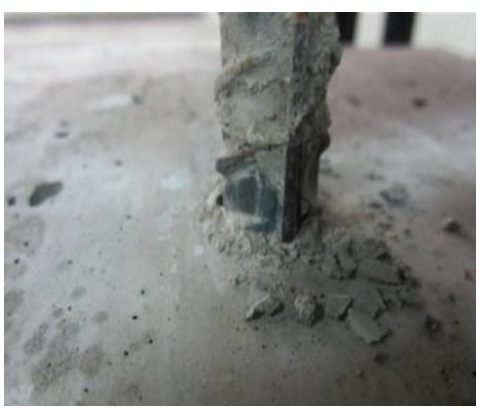

a) experiments [13]

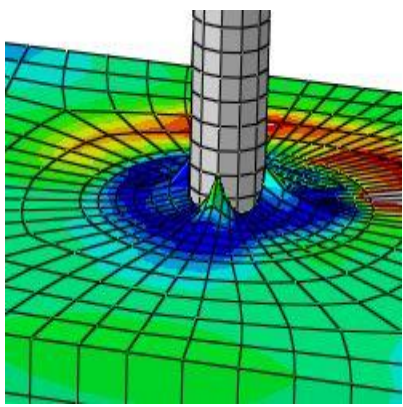

b) simulation in the present study

Fig. 5. The deformed profile

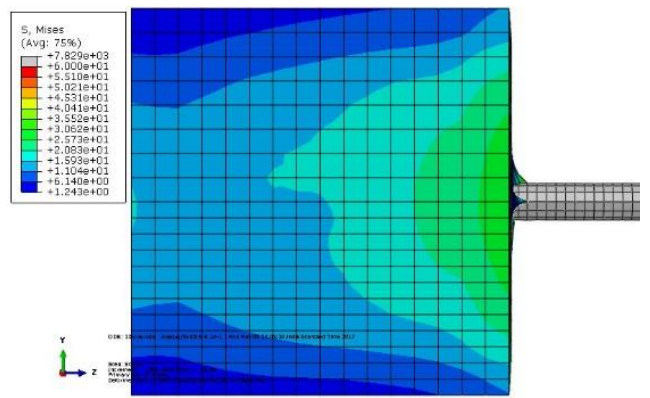

a) side view

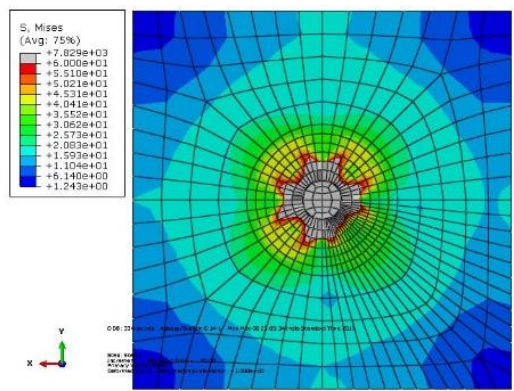

b) top view

Fig. 6. von-Mises stresses (MPa) in cubical specimens 
The red region represents the regions of maximum von mises stress in the concrete specimens. The stress was found to be as high as $55 \mathrm{MPa}$ in the concrete, see Fig. $6 b$.

The CU (relative displacement between the endpoints in the spring-like translator connector element) and the CTF (total force in the spring-like translator connector element) was obtained from the visualization module in the ABAQUS. The " $\mathrm{X}$ -Y data" function of ABAQUS was used to obtain stress versus slip. The total force was obtained i.e. the CTF were converted to bond stress values in $\mathrm{MPa}$ and was plotted to the bearing stress - slip graph with the help of Microsoft Excel. Fig. 7 shows the comparison of experimental and predicted results of the bond stress versus slip. It was found that the predicted results were found to be matching very well with the experimental results.

\section{Results and discussion}

The validated finite element model was used to identify the parameters influencing bond behavior pattern in reinforced concrete. The response of pullout for bars of different diameter has been studied. The variation of pullout response with strength of the concrete is also studied and presented here. The parameters considered for the study were diameter of the bars and the strength of concrete and the results of parametric study are discussed in this Section.

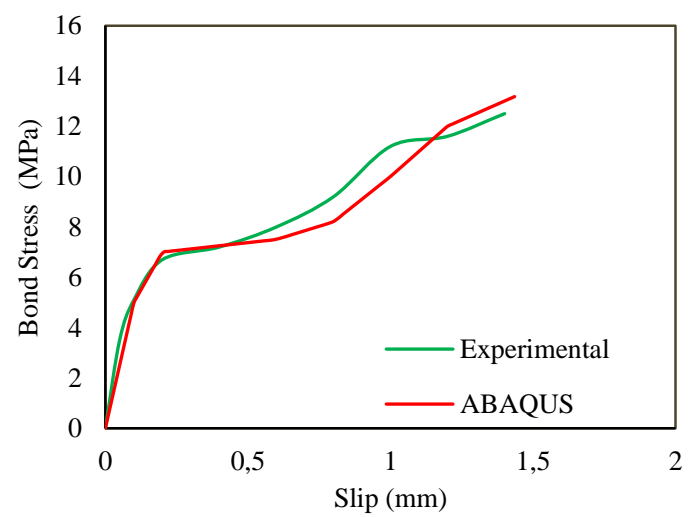

Fig. 7. Comparison of numerical and experimental results
The influence of varying concrete strength 20, 40, 60,80 and $100 \mathrm{MPa}$ on the pull out behavior of varying diameter of reinforcing bar diameter was studied. In first phase, the numerical results of the model of $16 \mathrm{~mm}$ diameter bar was compared with varying the concrete strength, see Fig. 8a. It is observed that the bond stress was found to increase with increase in strength. The $20 \mathrm{MPa}$ concrete showed a bond stress of $12.5 \mathrm{MPa}$ whereas the 40MPa concrete showed peak bond stress of 19.4 $\mathrm{MPa}$. The bond stress of $24.4 \mathrm{MPa}$ was achieved by $60 \mathrm{MPa}$ concrete embedded with $16 \mathrm{~mm}$ diameter bars. It was predicted further, that the $80 \mathrm{MPa}$ concrete showed bond strength of $29 \mathrm{MPa}$. However, it was observed that the peak bond stress value was achieved by that of $100 \mathrm{MPa}$ concrete with a value of $30.1 \mathrm{MPa}$. Analyzing the above values, it can be clearly seen that keeping the diameter of the bar constant, increase in concrete strength aided in the improvement of bond properties of concrete and steel. The value of slip for $20 \mathrm{MPa}$ was found to be $1.4 \mathrm{~mm}$ where as that of 40 and $60 \mathrm{MPa}$ was almost $1.6 \mathrm{~mm}$. The value of slip was also found to increase as the concrete strength increased from 20 to $80 \mathrm{MPa}$. The maximum value of slip among the five cases were $1.8 \mathrm{~mm}$ exhibited by $80 \mathrm{MPa}$ concrete embedded with $16 \mathrm{~mm}$ diameter bar.

In second phase, the numerical values of the model of $20 \mathrm{~mm}$ diameter bar was compared by varying the concrete strength, see Fig. 8b. It was observed that the bond stress was found to increase with increase of strength. The bond stress reached as high as $45 \mathrm{MPa}$ for $20 \mathrm{~mm}$ diameter bar along with $100 \mathrm{MPa}$ concrete. Fig. 8b shows the comparative study of $20 \mathrm{~mm}$ diameter bars with the varying compressive strength of concrete. The bond stress of concrete compressive strength 20 , 40, 60, 80 and $100 \mathrm{MPa}$ was found to be 16, 35, 37 and 43 and $45 \mathrm{MPa}$, respectively. The slip for all the cases was found to be around $2 \mathrm{~mm}$. The bond stress for $20 \mathrm{MPa}$ was observed to be $16.1 \mathrm{MPa}$ whereas that of $40 \mathrm{MPa}$ was found to be $31.2 \mathrm{MPa}$. The $60 \mathrm{MPa}$ concrete with $20 \mathrm{~mm}$ diameter bars embedded in it showed a bond strength of $37 \mathrm{MPa}$. The $80 \mathrm{MPa}$ concrete exhibited a bond strength of 
44.1 MPa. The highest bond stress $44 \mathrm{MPa}$ was observed against the $100 \mathrm{MPa}$ grade concrete.

In third phase, the numerical values of the model of $25 \mathrm{~mm}$ diameter bar was compared by varying the concrete strength and was found that with increase of strength the bond stress was also found to increase. Fig. 8c shows the results of parametric study conducted in ABAQUS on numerical models $25 \mathrm{~mm}$ diameter bars with varying composition of concrete with strength $20 \mathrm{MPa}, 40 \mathrm{MPa}, 60 \mathrm{MPa}, 80 \mathrm{MPa}$ and $100 \mathrm{MPa}$. The bond slip value for $20 \mathrm{MPa}$ concrete was found to be $1.6 \mathrm{~mm}$. The other grades of concrete were found to have bond slip values approximately equal to 2 $\mathrm{mm}$. The bond strength of $20 \mathrm{MPa}$ grade concrete was found to be $28.9 \mathrm{MPa}$, whereas in case of 40 $\mathrm{MPa}$ concrete was $48.4 \mathrm{MPa}$. The concrete strength of 60,80 and $100 \mathrm{MPa}$ was found to have bond stress values almost equal to the $60 \mathrm{MPa}$. There was only slight improvement of bond strength noticed when the concrete grade was increased from the 60 to $100 \mathrm{MPa}$. Therefore, it is concluded that the

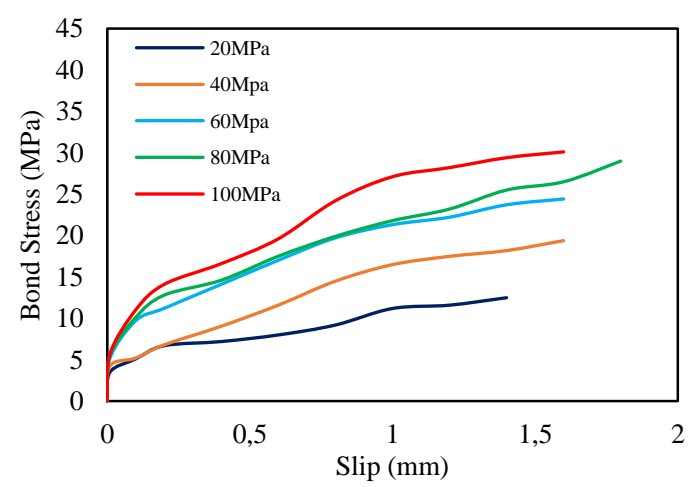

a) $16 \mathrm{~mm}$ diameter significant improvement in the bond strength was achieved between 20 and $40 \mathrm{MPa}$ grade concrete. An increase in bond stress less than $2 \%$ was achieved when concrete strength was increased from 60 to $100 \mathrm{MPa}$. Therefore, it is concluded that the bond stress was found to be unaffected with increase in concrete strength for high strength concrete like 60 to $100 \mathrm{MPa}$. The maximum deflection was observed between that of 20 and 40 $\mathrm{MPa}$ concrete along with $20 \mathrm{~mm}$ diameter bar, see Fig. 8(b). It was observed that the bond properties between concrete and steel greatly improved when $40 \mathrm{MPa}$ concrete as compared to $20 \mathrm{MPa}$ grade concrete embedded in case of $20 \mathrm{~mm}$ diameter bar. The bond stress was found to be unaffected with increase in concrete strength for high strength concrete like $60 \mathrm{MPa}, 80 \mathrm{MPa}$ and $100 \mathrm{MPa}$ embedded with $25 \mathrm{~mm}$ diameter bar. Therefore, it is concluded that the improvement in bond stress was found to be insignificant when concrete strength was increased from 60 to $100 \mathrm{MPa}$.

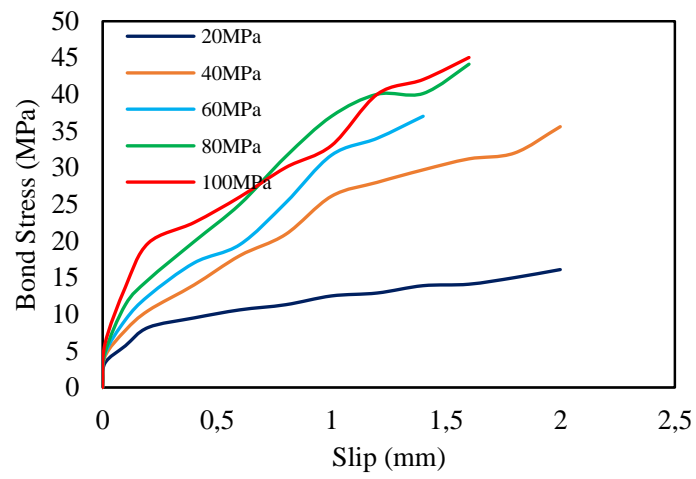

b) $20 \mathrm{~mm}$ diameter

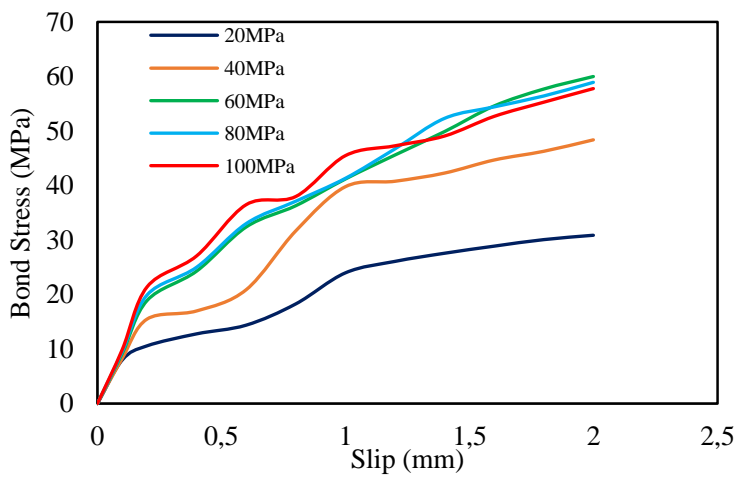

a) $25 \mathrm{~mm}$ diameter

Fig. 8. Parametric study by varying concrete strength 
The influence of varying reinforcement bar diameter against $20 \mathrm{MPa}$ concrete was studied in light of bond stress versus slip is shown in Fig. 9. It was found that with increase of diameter of the bar the bond strength also increased as shown in Fig. 9a. The maximum bond stress corresponding slip characteristics embedded with $16 \mathrm{~mm}, 20 \mathrm{~mm}$ and $25 \mathrm{~mm}$ diameter bars was 12,16 and $31 \mathrm{MPa}$, respectively. The $16 \mathrm{~mm}$ bars when embedded in $20 \mathrm{MPa}$ concrete showed a bond stress value of $12.5 \mathrm{MPa}$. For the $20 \mathrm{~mm}$ diameter bars and $25 \mathrm{~mm}$ diameter bars the bond stress values were found to be 16.1 and $31 \mathrm{MPa}$, respectively. Therefore, it was concluded that the bond stress was found to be increased with increase of reinforcing bar diameter. There is a clear increase in slip was observed on 16 and $20 \mathrm{~mm}$ diameter reinforcing bars and the maximum difference in slip almost $0.5 \mathrm{~mm}$. For all the three cases, the difference in slip between the $20 \mathrm{~mm}$ and $25 \mathrm{~mm}$ diameter bars was found to be negligible. It is also observed that the slip of reinforcing bar was found to be increased with increase in bar diameter of up to $20 \mathrm{~mm}$.

The variation of bond stress with the variation of bar diameter against $40 \mathrm{MPa}$ concrete is shown in Fig 9(b). It was found that with increase of diameter of the bar there was a considerable increase in the bond stress. The bond stress for 16 $\mathrm{mm}$ diameter bar with $40 \mathrm{MPa}$ concrete was found to be $19.4 \mathrm{MPa}$ whereas the $20 \mathrm{~mm}$ diameter bar showed a value of $35.6 \mathrm{MPa}$. The $25 \mathrm{~mm}$ diameter bars embedded in concrete of strength $40 \mathrm{MPa}$ showed the maximum bond strength with bond stress value of $48.4 \mathrm{MPa}$. The improvement in bond stress when bar diameter was increased from 16 to $20 \mathrm{~mm}$ was found to be around $60 \%$. These data are a clear indication that with the increase of size of diameter of bars keeping the concrete strength constant the bonding properties of concrete increased. The slip was also followed an increasing trend from 16 to $25 \mathrm{~mm}$ diameter bars. The maximum difference in slip between 16 and $20 \mathrm{~mm}$ diameter bars was found to be as large as $0.45 \mathrm{~mm}$.

The variation of bond stress with the varying reinforcing bar diameter $(16 \mathrm{~mm}, 20 \mathrm{~mm}, 25 \mathrm{~mm})$ for
$60 \mathrm{MPa}$ concrete was compared, see Fig. 9c. It was found that with increase of diameter of the bar the there was a considerable increase in the bond stress. In case of $60 \mathrm{MPa}$ concrete with $16 \mathrm{~mm}$ diameter bars showed a bond stress of 24.4 MPa. The bond stress was found to be improved significantly for the case of $20 \mathrm{~mm}$ bars to $37 \mathrm{MPa}$. It was observed that the maximum bond stress among the three cases was that for the $25 \mathrm{~mm}$ diameter bars equal to $60 \mathrm{MPa}$. Hence it was concluded that with increase in bar size the bonding properties between concrete greatly improved. The slip of reinforcing bar was also found to increase with increase in bar diameter. The slip of 16 and $20 \mathrm{~mm}$ diameter bar was almost found to be equal. There was notable difference in slip when the reinforcing bar compared between 20 and $25 \mathrm{~mm}$ diameter i.e. $0.5 \mathrm{~mm}$.

The top view of concrete specimens with 60 $\mathrm{MPa}$ strength with $16 \mathrm{~mm}, 20 \mathrm{~mm}$ and $25 \mathrm{~mm}$ diameter bars was considered and the von-Mises stresses on the deformed concrete are shown in Fig. 10. Fig. 10a shows the deformed profile of $60 \mathrm{MPa}$ concrete embedded with $16 \mathrm{~mm}$ diameter bars. The grey color in the profile shows the rebar region and the area around the concrete region. The maximum stress observed in the concrete was around $40 \mathrm{MPa}$. The stress variation was observed from the near end to far end of the rebar. Fig. 10b shows the deformed profile of the concrete embedded with $20 \mathrm{~mm}$ diameter bars. Maximum stress was observed in the rebar shown by the grey color. A maximum of 50 MPa stress was observed on the concrete surface shown by the red region. The gradual decrease of von mises stress was observed away from the rebar represented by the green and yellow color. The minimum von mises stress was observed at the region farther away represented by the dark blue color. Fig. 10c shows the deformed profile of concrete embedded with $25 \mathrm{~mm}$ diameter bars. The maximum von mises stress on the concrete was found to be in the range of $60 \mathrm{MPa}$ represented by the red color. 


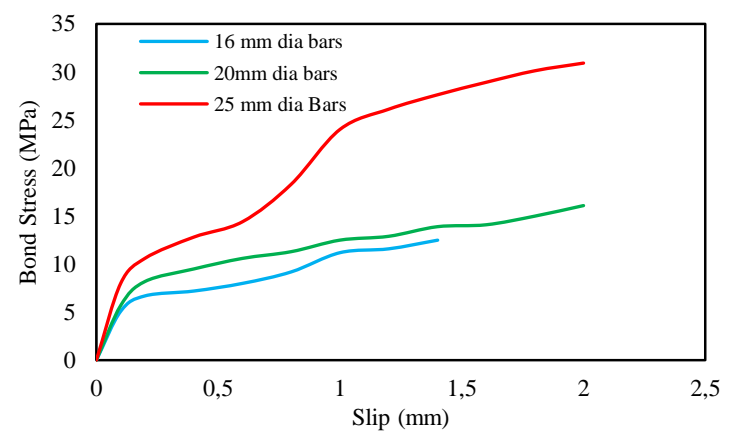

a) $20 \mathrm{MPa}$ concrete

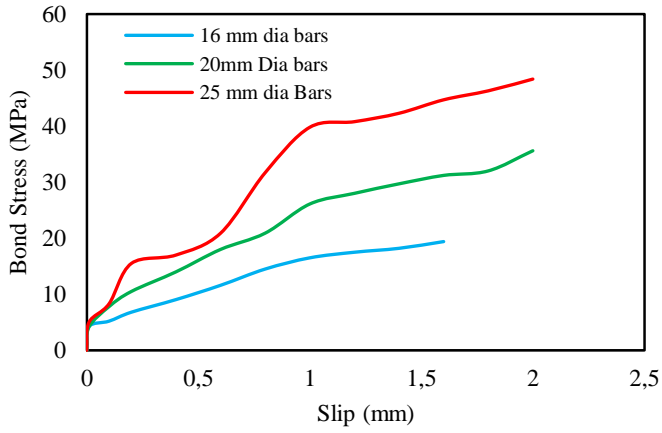

b) $40 \mathrm{MPa}$ concrete

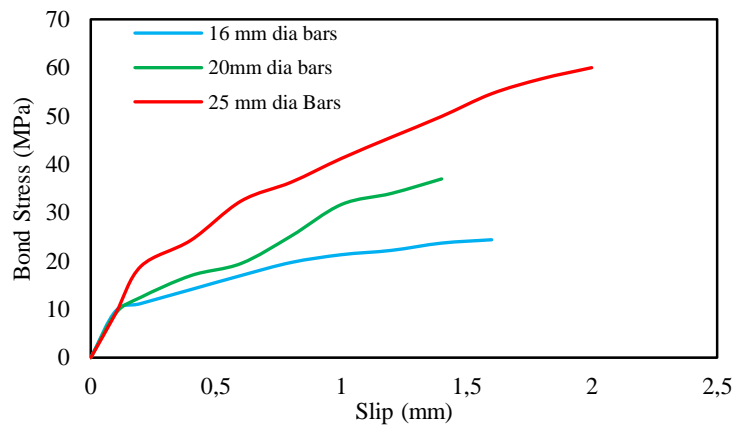

c) $60 \mathrm{MPa}$ concrete

Fig. 9. Parametric study by varying bar diameter

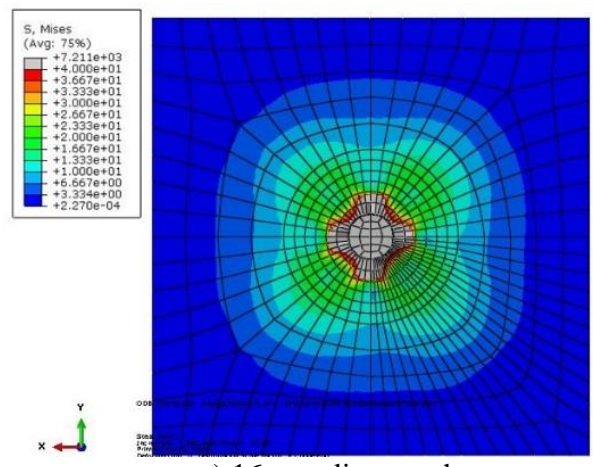

a) $16 \mathrm{~mm}$ diameter bars

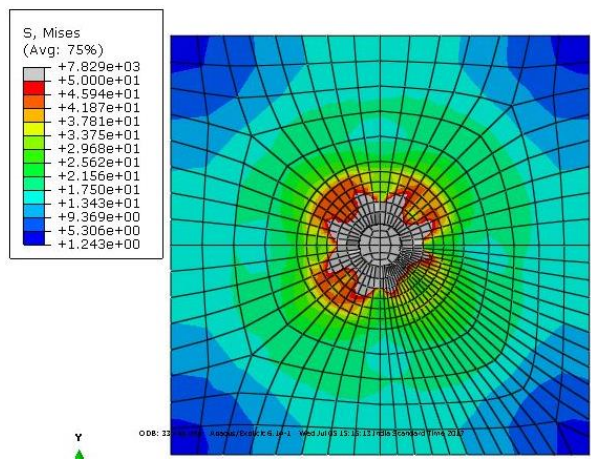

b) $20 \mathrm{~mm}$ diameter bars

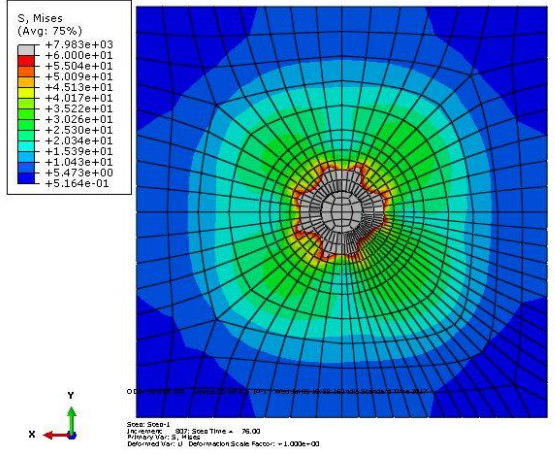

c) $25 \mathrm{~mm}$ diameter bars

Fig. 10. Von-Mises stresses (MPa) of concrete 


\section{Conclusions}

A 3D finite element model was developed to simulate the bond behavior that exists between concrete and steel in reinforced concrete material using ABAQUS software. The spring like translator, a connector element available in ABAQUS, was used to simulate the bond phenomena between concrete and steel. The results thus predicted through simulations were compared with the experimental results available in literature. The parameters considered in the present study were the diameter, 16, 20 and $25 \mathrm{~mm}$ and the concrete strength of $20,40,60,80$ and $100 \mathrm{MPa}$. The major conclusions that was drawn from the study are presented below.

- The results present that the translator did an efficient job in simulating the bond behavior. It was also found that the predicted and measured deformed profile was found in good agreement.

- In case of $40 \mathrm{MPa}$ concrete the bond stress improved by $60 \%$ when $16 \mathrm{~mm}$ diameter bars were replaced by $20 \mathrm{~mm}$ diameter bars. Increasing the bar diameter is an efficient method to improve the bond strength characteristics.

- From the parametric study it is observed that increasing the concrete strength improved the bond strength characteristics. The bond stress was found to be unaffected with increase in concrete strength for high strength concrete like 60 - $100 \mathrm{MPa}$ embedded with $25 \mathrm{~mm}$ diameter bar

\section{References}

[1] Jiang DH, Shah SP, Andonian AT (1984) Study of the transfer of tensile forces by bond. International Concrete ACI Journal of Proceeding 81: 251-259.

[2] Soroushian P, Choi KB (1989) Local bond of deformed bars with different diameters in confined concrete. ACI, Structural Journal 86(2): 217-222.

[3] Abrishami HH, Mitchell D (1992) Simulation of uniform bond stress. Materials Journal ACI 89(2): 161-168.
[4] Malvar LJ (1992) Bond of reinforcement under controlled confinement. Materials Journal 89(6): 593-601.

[5] Yankelevsky DZ, Adin MA, Farhey DN (1992) Mathematical model for bond-slip behavior under cyclic loading. ACI Structural Journal 89(6): 692-698.

[6] Harajli MH, Hamad BS, Rteil AA (2004) Effect of confinement of bond strength between steel bars and concrete. ACI Structural Journal 101(5): 595-603.

[7] Li X. Finite element modeling of skewed reinforced concrete bridges and the bond-slip relationship between concrete and reinforcement. MSc Thesis, Auburn University, 2007.

[8] Shafaie J, Hosseini A, Marefat MS. 3D finite element modelling of bond-slip between rebar and concrete in pull-out test. Third International Conference on Concrete and Development, 2009, Tehran, Iran.

[9] Rao GA, Pandurangan K, Sultana F, Eligehausen R. Studies on the pull-out strength of ribbed bars in high-strength concrete. Proceedings of Fracture Mechanics in Concrete and Concrete Structures-6, Catania, 295-301, 2010, Italia.

[10] Barbosa MTG, Filho SS (2013) Investigation of bond stress in pull out specimens with high strength concrete. Global Journal of Research Engineering-Civil and Structural Engineering 13(3): 55-64.

[11] Filho A, Debs MKE, Debs ALHC (2014) Numerical approach of the bond stress behavior of steel bars embedded in self-compacting concrete and in ordinary concrete in pullout models. Science and Engineering Journal 23(2): 57-66.

[12] Prince M, Singh B (2015) Bond behaviour of normal and high strength recycled aggregate concrete. Structural Concrete 16(1): 56-70.

[13] Xing G, Zhou C, Wu T, Liu B (2015) Experimental study on bond behavior between plain reinforcing bars and concrete. Advances in Material Science Engineering 1-9.

[14] ABAQUS, 2008. User's manual, Version 6.10. 1. Dassaults Systemes Inc.

[15] Johnson GR, Cook WH (1985) Fracture characteristics of three metals subjected to various strains, strain rates, temperatures and pressures. Engineering Fracture Mechanics 21(1): 31-48. 
[16] Borvik T, Hopperstad OS, Berstad T, Langseth M (2001) A computational model of viscoplasticity and ductile damage for impact and penetration. European Journal of Mechanics and Solids 20: 685-712.
[17] Nilson AH (1968) Nonlinear analysis of reinforced concrete by the finite element method. ACI Journal of Proceeding 65(9): 757-766. 